\title{
A rare chest X-ray sign in the diagnosis of an intracardiac bullet: case report
}

\author{
Mohamed Osman ${ }^{1 *}$ (D), Reham Khalil ${ }^{2}$, Ahmed Hany Abdalla ${ }^{3}$, Azza Katta ${ }^{4}$, Samer Nashef ${ }^{5}$ and Sameh Elameen ${ }^{1}$
}

\begin{abstract}
Background: Gunshot injuries to the heart are often seen in cardiac surgical practice. Victims are usually investigated with various types of imaging modalities, including simple chest $X$-ray (CXR) which is a primary imaging modality that can easily locate a bullet and is useful in monitoring before surgical intervention as bullets may migrate.

Case presentation: A 32-year-old man was admitted as an emergency in a primary hospital after being injured by a gunshot to the chest. The bullet entry was over the back of the left shoulder with no exit point seen. The chest $X$-ray showed left pleural effusion and a retained intrathoracic bullet. A chest drain was inserted and drained 2200 $\mathrm{ml}$ of blood. Computed tomography (CT) scan showed an intracardiac bullet associated with left lower lobe contusion and left-sided hemothorax. He was urgently transferred to theater for exploration via left thoracotomy. The bullet could not be found so the inlet point in the left ventricle was sutured. After stabilizing the patient, he was referred to a specialized cardiac center for further management.

The patient arrived at our center 2 days after the injury, fully conscious and hemodynamically stable. On arrival, chest $\mathrm{X}$-rays were obtained to rule out possible migration of the bullet and revealed that the retained bullet was still within the cardiac silhouette. The X-ray appearance of the bullet showed a characteristically double contour, strongly suggesting that the bullet had lodged in the heart muscle and was moving with each heartbeat. The patient was transferred to the theater for median sternotomy. The aorta, superior vena cava, and inferior vena cava were cannulated, and cardiopulmonary bypass was initiated. The aorta was cross-clamped and the cardioplegia was given. Palpation of the still heart readily identified the bullet within the interventricular septum. The left ventricle was opened $1 \mathrm{~cm}$ from the left anterior descending artery just on top of the bullet. The bullet was successfully retrieved. The bullet was transfixing the septum causing a small ventricular septal defect which was closed using a Teflon patch and the ventricle was repaired.

Conclusion: The double contour appearance of the bullet indicates that the bullet is moving and strongly suggests an intramyocardial position.
\end{abstract}

\section{Background}

Gunshot injuries to the heart are often seen in cardiac surgical practice. In 2009, the World Health Organization reported 1217 cases of assault by guns and rifles in Egypt [1]. Victims are usually investigated with various types of imaging modalities, including simple chest X-ray (CXR). We report a rare CXR sign with a high diagnostic value in

\footnotetext{
* Correspondence: m.a.othman@gmail.com

${ }^{1}$ Cardiac Surgery Department, National Heart Institute, Cairo, Egypt

Full list of author information is available at the end of the article
}

a case of an intracardiac bullet. This sign was described earlier by Demetrios and Jeffrey in 2000 [2].

\section{Case presentation}

A 32-year-old man was admitted as an emergency in a primary hospital after being accidentally injured by a gunshot to the chest from a distance. The bullet entry wound was over the back of the left shoulder with no exit point seen (Fig. 1a). CXR showed left pleural effusion and a retained intrathoracic bullet. A chest drain was inserted and drained $2200 \mathrm{ml}$ of blood. The patient

\section{Springer Open}

() The Author(s). 2020 Open Access This article is licensed under a Creative Commons Attribution 4.0 International License, which permits use, sharing, adaptation, distribution and reproduction in any medium or format, as long as you give appropriate credit to the original author(s) and the source, provide a link to the Creative Commons licence, and indicate if changes were made. The images or other third party material in this article are included in the article's Creative Commons licence, unless indicated otherwise in a credit line to the material. If material is not included in the article's Creative Commons licence and your intended use is not permitted by statutory regulation or exceeds the permitted use, you will need to obtain permission directly from the copyright holder. To view a copy of this licence, visit http://creativecommons.org/licenses/by/4.0/. 


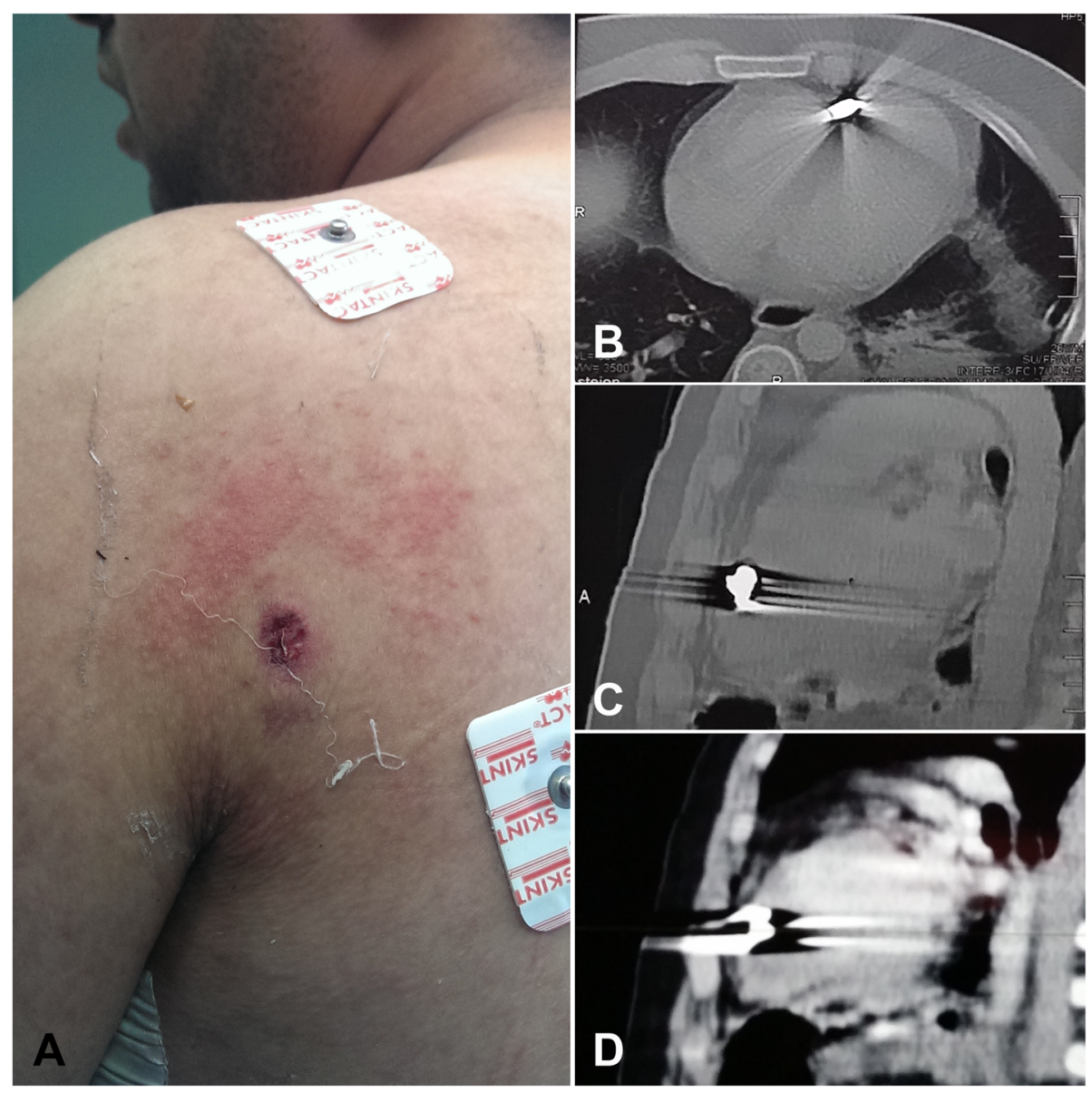

Fig. 1 a The bullet inlet at the left shoulder. b-d CT scan cuts show the bullet within the heart

received two units of blood and $3000 \mathrm{ml}$ of crystalloids as resuscitative measures. Computed tomography (CT) scan showed an intracardiac bullet associated with left lower lobe contusion and left-sided hemothorax (Fig. 1b-d). He was urgently transferred to the operating room (OR) for exploration via left thoracotomy as he continued to bleed through chest drain. The aim of the exploration was to repair possible tear in the lung or the ventricle. There was minimal pericardial collection, the bullet could not be found so the inlet point in the left ventricle was sutured using a 4-0 Prolene. After stabilizing the patient, he was referred to a specialized cardiac center for further management.

The patient arrived at our center 2 days after the injury, fully conscious, well oriented, and hemodynamically stable with fair vital signs. On arrival, antero-posterior and lateral chest X-rays were obtained to rule out possible migration of the bullet and revealed that the retained bullet was still within the cardiac silhouette. The X-ray appearance of the bullet showed a characteristically double contour (Fig. 2a-c), strongly suggesting that the bullet had lodged in the heart muscle and was moving with each heartbeat, rather than mobile within the cardiac chambers as it had the same location in two sets of CXRs 2 days apart. Electrocardiography excluded ischemic changes and echocardiogram excluded septal defects or valve disruption; it also suggested the presence of the bullet in within the septum.

The patient was transferred to the theater for median sternotomy. The aorta, superior vena cava, and inferior vena cava were cannulated, and cardiopulmonary bypass was initiated. The aorta was cross-clamped and the heart arrested with cold crystalloid cardioplegia. This was done to minimize the chance of bullet embolization before manipulating the heart. The bullet inlet into the ventricle was inspected (lateral wall) (Fig. 3a), and palpation of the still heart readily identified the bullet within the interventricular septum. In the hope of reducing tissue damage, unsuccessful attempts were made to reach the bullet via both atria. Finally, the left ventricle was opened $1 \mathrm{~cm}$ from the left anterior descending artery midway between the apex and outflow tract just on top of the bullet (Fig. 3b). The bullet (9-mm ka pistol) was successfully retrieved (Fig. 3c-e). The bullet was 


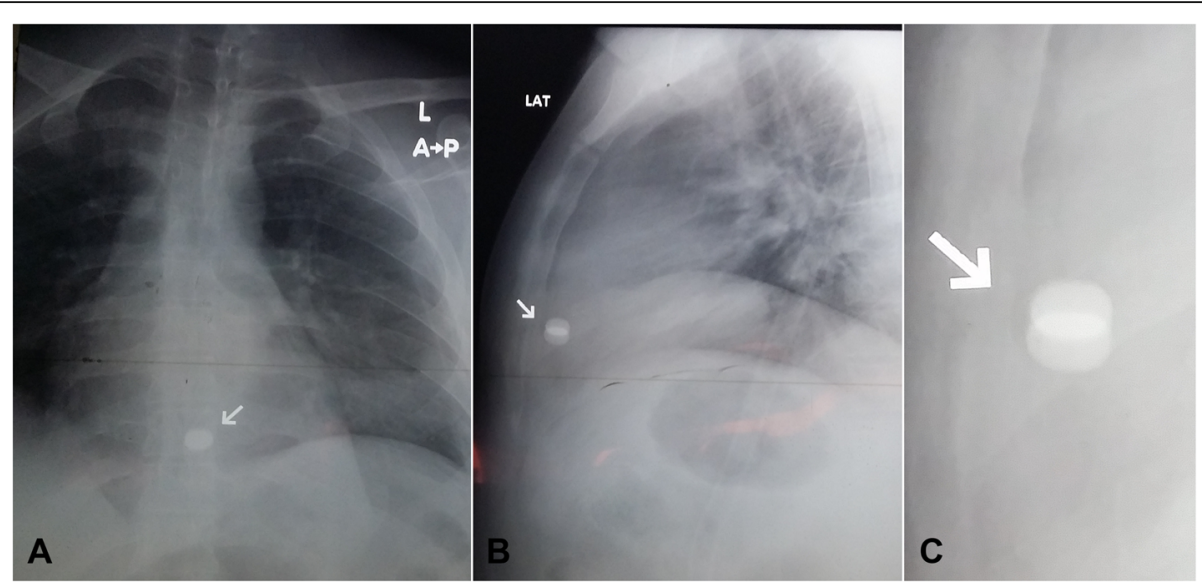

Fig. 2 a Antero-posterior CXR showing the bullet within the cardiac silhouette. b, c Lateral CXR showing the characteristic double contour of the bullet

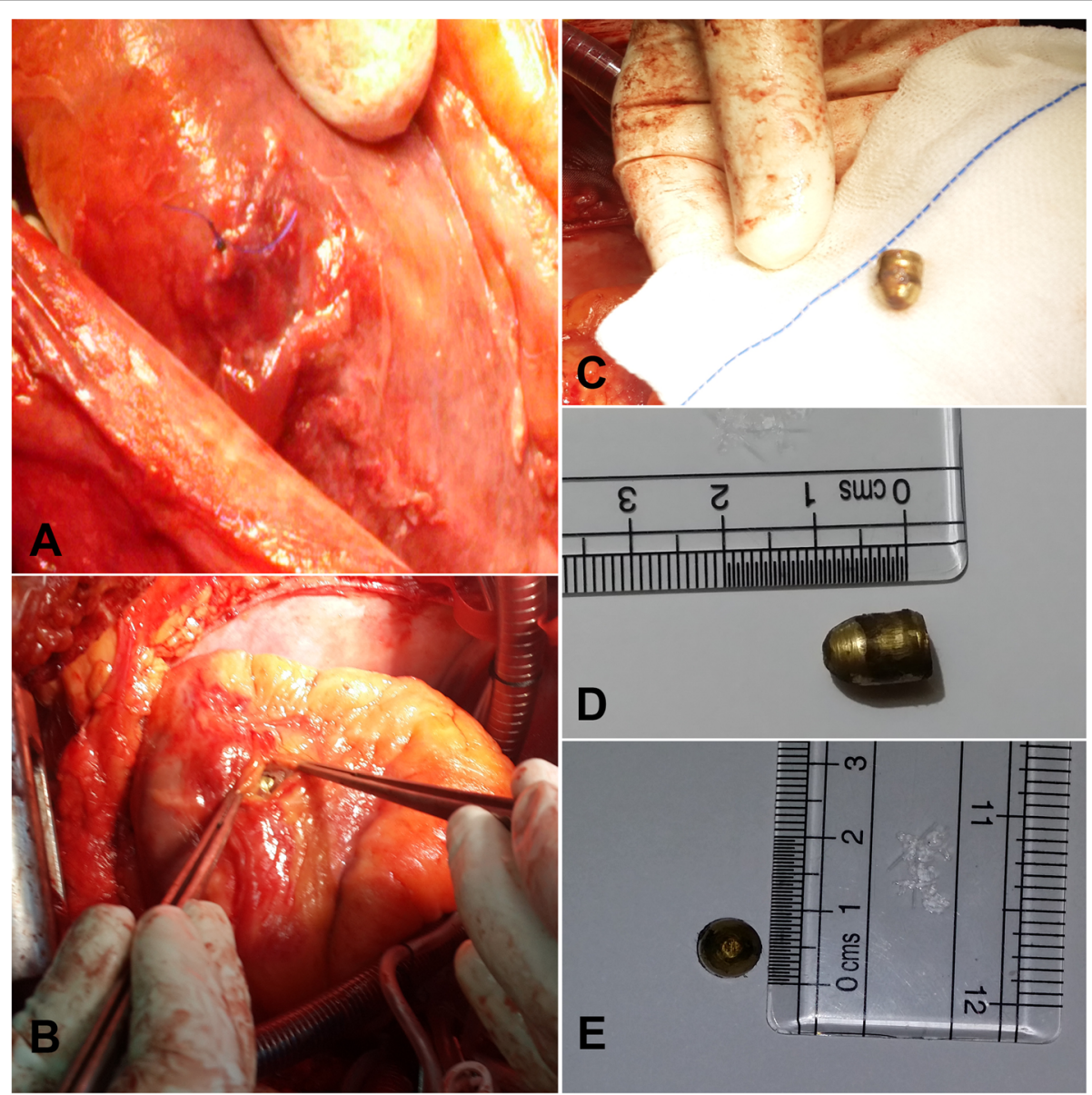

Fig. 3 a The bullet inlet point to the ventricle as seen during second exploration. $\mathbf{b}$ The bullet within the ventricle after ventriculotomy. $\mathbf{c}-\mathbf{e}$ The bullet after extraction 
transfixing the septum causing a small ventricular septal defect (VSD) which was occluded by the bullet itself. The VSD was closed using a Teflon patch and the ventricle was repaired. The patient was smoothly weaned from bypass after an ischemic time of $25 \mathrm{~min}$ and a bypass time of $45 \mathrm{~min}$ and made an uneventful recovery.

\section{Discussion}

The mortality of transmediastinal gunshot injuries is between 40 and $80 \%$ [3, 4]. Management depends on the stability of the patients and the time of presentation.

As a missile traverses the body, it causes injury by transferring some or all of its available energy, and this is manifested by lacerating and crushing tissues in its path and, in some cases, injury remote from the missile path. The resulting damage depends on the velocity (KE $=1 / 2 M V^{2}$ ), injured organs, and the efficiency of first aid. $\mathrm{KE}=1 / 2 \mathrm{M}\left(\mathrm{V} 1^{2}-\mathrm{V} 2^{2}\right)$, where $\mathrm{KE}$ is the available energy, $\mathrm{M}$ is the mass, and V1and V2 are the velocities at entry and at exit, respectively.

In general, bullets fired from handguns are propelled at a low velocity, have low available energy (100-500 J), and result in low-energy transfer wounds. Jonathan et al. recommended that exploration with treatment of the cardiac injury is warranted in the patient who presents with hemorrhage, great vessel injury, or tamponade. Missiles with low-risk characteristics (immobile rightsided, smooth, small $[<5 \mathrm{~mm}]$, or completely intramyocardial) that demonstrate no complications on initial and serial imaging may be managed non-operatively [5].

Patients with chest gunshot wounds should be investigated by different imaging modalities including CXR, CT scan, fluoroscopy, C-arm, and echocardiogram. The latter is important to exclude tamponade, VSD, and valve injury.

CXR is a simple primary imaging modality that can easily locate a bullet and is useful in monitoring before surgical intervention as bullets may migrate. The clue to diagnosis in this case was the double contour for the bullet on CXR, suggesting the bullet is intramyocardial, moving with each heartbeat during X-ray exposure. We report our case with this characteristic sign to draw attention to this sign in the diagnosis and management of bullet injuries. This feature was previously described by Demetrios and colleagues [2].

Fluoroscopy is a good tool to localize the bullet and to show its movement within the heart; however, it was not used in our case.

CT scan is particularly useful for delineating the trajectory of a bullet and detection of extra-cardiac associated injuries, thus directing subsequent examinations and treatment plan [6]. Additionally, CT angiography can be useful for the early diagnosis of vascular injuries of the great vessels and coronary arteries [3]. New technology as ECG-gated CT imaging has improved image quality and thus the diagnostic confidence in the preoperative localization of metallic foreign bodies in relatively rapid heart rates $[6,7]$.

We chose median sternotomy and the use of cardiopulmonary bypass $(\mathrm{CPB})$ as we knew that the bullet is mostly intracardiac. Sternotomy gives excellent exposure of the heart with the option of using the CPB. We clamped the aorta before manipulating the heart to avoid bullet embolization. To retrieve the bullet, we started with the least invasive approaches first: right then left atrium, before ventriculotomy.

\section{Conclusion}

Bullet injuries to the chest should be investigated by recent CXR to confirm the position of the bullet before surgical intervention. The double contour appearance of the bullet indicates that the bullet is moving and strongly suggests an intramyocardial position.

\section{Abbreviations \\ CT: Computed tomography; CXR: Chest X-ray; OR: Operating room; VSD: Ventricular septal defect; KE: Kinetic energy}

\section{Acknowledgments}

Not applicable.

\section{Authors' contributions}

All authors contributed equally in the case report as follows: MO operated on the patient as the first surgeon and wrote the draft copy of the case report; $\mathrm{RH}$ analyzed and reported the $\mathrm{CT}$ scan and the chest X-ray; $\mathrm{AH}$ anesthetized the case and searched the literature and collected the data to write the case report; AK performed and reported the Echo; SN wrote and revised the manuscript and the discussion; and SA operated in the case and prepared and revised the manuscript. All authors have read and approved the manuscript.

\section{Funding}

I, Mohamed Osman, hereby declare that we as authors have not receive any funds for this case report.

\section{Availability of data and materials}

The datasets used and/or analyzed during the current study/case report are available from the corresponding author on reasonable request.

\section{Ethics approval and consent to participate}

This is a case report and not a study. However, the ethical committee in our trust is approving the publication of this case report. There were no animal/ plants involved in this case.

\section{Consent for publication}

I, Mohamed Osman, hereby declare that this case report is sent for publication after having the patient's consent as per our hospital policy. Written and verbal consents were obtained before taking any photos or sending any imaging for publication.

\section{Competing interests}

None.

\section{Author details}

${ }^{1}$ Cardiac Surgery Department, National Heart Institute, Cairo, Egypt. ${ }^{2}$ Radiology Department, Ain Shams University, Cairo, Egypt. ${ }^{3}$ Anaesthesia Department, National Heart Institute, Cairo, Egypt. ${ }^{4}$ Cardiology Department, National Heart Institute, Cairo, Egypt. ${ }^{5}$ Cardiothoracic Surgery Department, Royal Papworth Hospital, Cambridge, UK. 
Received: 25 February 2020 Accepted: 12 May 2020

Published online: 27 May 2020

\section{References}

1. Injury surveillance: a tool for decision-making: annual injury surveillance report, Egypt, 2009

2. Jeffrey K, Demetrios D (2000) Retained cardiac missile: an unusual case report. J Trauma Injury Infec Crit Care 48(2):312

3. Burack JH, Kandil E, Sawas A et al (2007) Triage and outcome of patients with mediastinal penetrating trauma. Ann Thorac Surg 83(2):377e82

4. Okoye OT, Talving P, Teixeira PG et al (2013) Transmediastinal gunshot wounds in a mature trauma centre: changing perspectives. Injury 44(9): $1198 \mathrm{e} 203$

5. Jonathan B, Eric K, Jason M et al (2009) Conservative management of retained cardiac missiles: case report and literature review. J Surg Educ 66(4):228-235

6. Ibirogba S, Nicol AJ, Navsaria PH (2007) Screening helical computed tomographic scanning in haemodynamic stable patients with transmediastinal gunshot wounds. Injury 38(1):48e52

7. Hachulla A-L, Ronot M, Noble S et al (2016) ECG-triggered high-pitch CT for simultaneous assessment of the aorta and coronary arteries. J Cardiovasc Comput Tomogr 10(5):407e13

\section{Publisher's Note}

Springer Nature remains neutral with regard to jurisdictional claims in published maps and institutional affiliations.

\section{Submit your manuscript to a SpringerOpen ${ }^{\circ}$ journal and benefit from:}

- Convenient online submission

- Rigorous peer review

- Open access: articles freely available online

High visibility within the field

- Retaining the copyright to your article

Submit your next manuscript at $\boldsymbol{\nabla}$ springeropen.com 